\title{
Combination of Terrestrial and Satellite Gravity Data for the Characterization of the Southwestern Coastal Region of Cameroon: Appraisal for Hydrocarbon Exploration
}

\author{
Paul Gautier Kamto $\mathbb{D},{ }^{1,2}$ Willy Lemotio $\mathbb{D}^{1,2}$ Alain-Pierre Kamga Tokam, ${ }^{3}$ \\ and Loudi Yap (i) ${ }^{1,2}$ \\ ${ }^{1}$ Research Laboratory in Geodesy, National Institute of Cartography, Yaounde, Cameroon \\ ${ }^{2}$ Laboratory of Geophysics and Geoexploration, Department of Physics, University of Yaounde I, Yaounde, Cameroon \\ ${ }^{3}$ National Higher Polytechnic School Douala, University of Douala, Douala, Cameroon \\ Correspondence should be addressed to Paul Gautier Kamto; gautier1994@yahoo.fr
}

Received 12 February 2021; Accepted 11 June 2021; Published 25 June 2021

Academic Editor: Angelo De Santis

Copyright (C) 2021 Paul Gautier Kamto et al. This is an open access article distributed under the Creative Commons Attribution License, which permits unrestricted use, distribution, and reproduction in any medium, provided the original work is properly cited.

\begin{abstract}
The southwestern coastal region of Cameroon is an area of interest because of its hydrocarbon potential (gas and oil). Terrestrial and satellite gravity data were combined and analyzed to provide a better precision in determining the structure of the study area. Firstly, the two gravity databases (in situ and satellite) have been coupled and validated using the least square collocation technique. Then, spectral analysis was applied to the combined Bouguer anomaly map to evaluate the thickness of sediments in some localities. We found that the sedimentary cover of the southwestern coastal region of Cameroon has a thickness that varies laterally from $1.68 \pm 0.08$ to $2.95 \pm 0.15 \mathrm{~km}$, especially in the western part. This result confirms that our target area is a potential site for hydrocarbon exploration. The horizontal gradient method coupled with the upward continuation at variable heights has been used to highlight several lineaments and their directions (N-S, E-W, SW-NE, and SSW-NNE). Lineaments trending in an N-S orientation are predominant. The Euler deconvolution method was also applied to the Bouguer anomaly map to determine the position, orientation, and depth of the different superficial faults of the study area. It appears that the majority of superficial faults have an N-S and SSW-NNE orientation. These directions are correlated with those previously highlighted by the maxima of horizontal gradient. The structural map could be used for a better identification of the direction of fluid flow within the subsurface or to update the geological map of our study area.
\end{abstract}

\section{Introduction}

Our study area is located in southwest Cameroon, along the edge of the Atlantic Ocean (Figure 1). It is an epicontinental passive margin formed following the opening of the Atlantic Ocean. During several years, the southwestern coastal region of Cameroon has been the subject of several geophysical studies. The presence of the three major contacts in the north of the study area (Kribi-Edea area) has been identified in the previous study [1]. This work noted the presence of a highdensity intrusive igneous body in the upper part of the crust. Later, a study [2] has also identified major lineaments in the
Kribi-Edea area. Further studies [3] allowed localizing an intrusive body in the northwestern part of Kribi-Campo. An additional study [4] has evaluated the depth of the mafic interface under the transition zone between the southwestern coastal region of Cameroon and the northwestern part of Congo Craton; they showed that an uplift of the mafic interface at depths between 15.6 and $17 \mathrm{~km}$ led to a thinning of the crust under the study area. A recent study [5] shows that the study area is full of a better oil potential on the eastern part and constitutes a good hydrocarbon reservoir. The southwestern coastal region of Cameroon is therefore an area of interest because of hydrocarbon potential. 


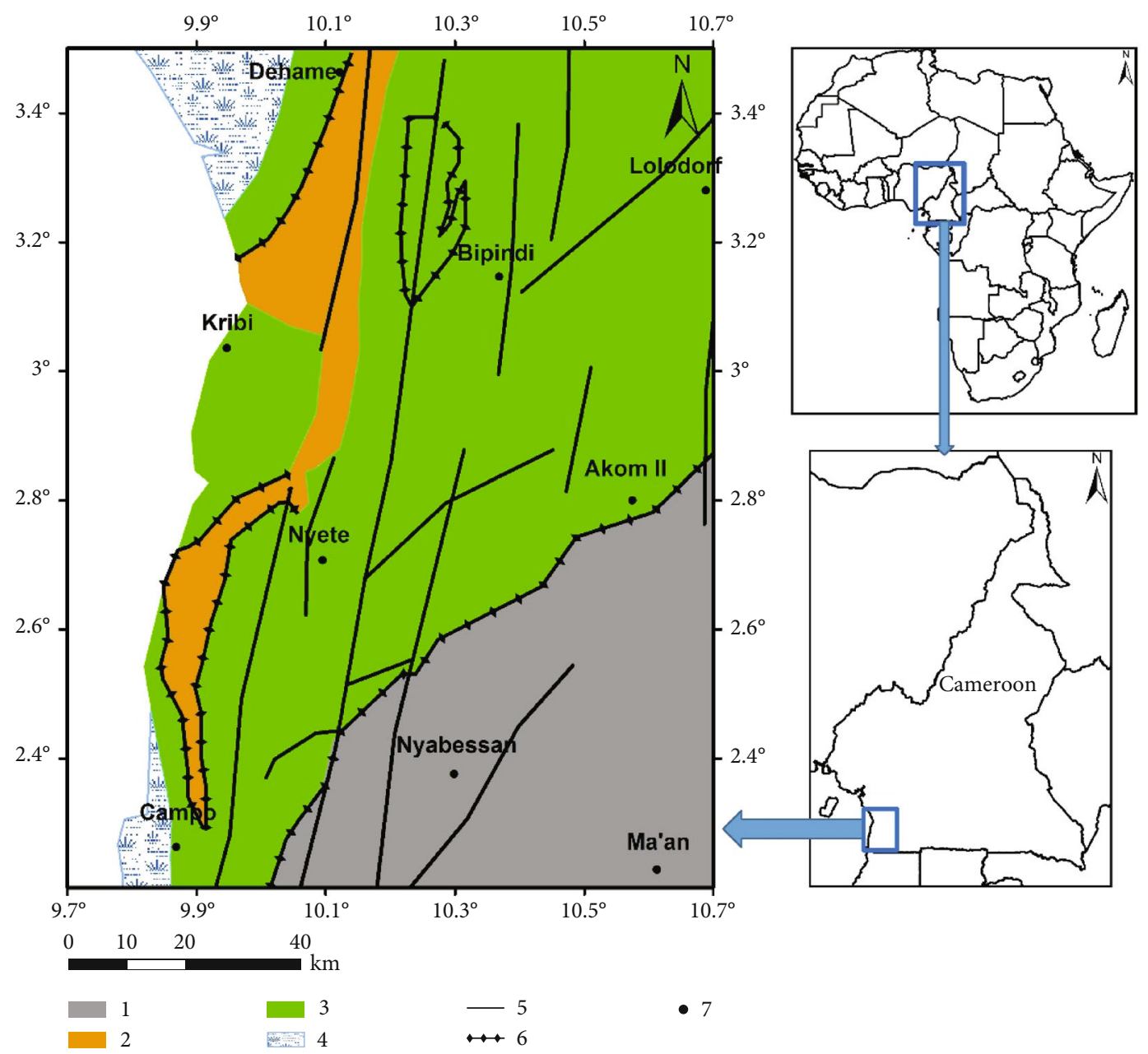

FIGURE 1: Simplified geological map of the study area showing major lithological and structural units. 1: arched basement; 2: Neoproterozoic cover; 3: Neoarchean and Paleoproterozoic cover; 4: post-Pan-African coverage; 5: fault; 6: thrust; 7: location.

The gravimetric method is widely used to characterize shallow and deep structures of Cameroon [3, 6-9]. However, this method could have some limitations depending on whether we use terrestrial or satellite gravity data. In fact, the terrestrial gravity data available in Cameroon are very sparse and contain many gaps in inaccessible areas. Poor spatial distribution is observed, particularly in coastal regions which are very rich in gas and oil. The use of satellite gravity models could greatly improve this deficit. These models offer gravity data with a good spatial resolution and an appreciable precision. Satellite gravity models (global geopotential models) also have some limitations. The gravity signal derived from these models is subject to omission error [10]. Omission error includes short wavelengths in the earth's gravity field that are not represented by global geopotential models [11]. Unlike satellite gravity data, terrestrial gravity data contains all possible medium-to-short wavelengths of the earth's gravity field. So the combination of the two types of gravity data (terrestrial and satellite) is necessary in order to improve the accuracy and consistency of our database.

The aim of this work is to combine terrestrial and satellite gravity data to provide better precision in characterizing the southwestern coastal region of Cameroon. To perform this work, we highlight the different contact zones (faults, fractures, and lineaments), mainly areas including high sedimentary thicknesses. These areas are recognized as potential sites for future hydrocarbon explorations. The methods used in this work are regional/residual separation, spectral analysis, horizontal gradient, and Euler deconvolution.

\section{Geological and Tectonic Context}

The geological history of the southwestern coastal region of Cameroon shows a particular interest since the separation of South America and Africa during the Cretaceous age [12]. Therefore, the filling of this coastal region with continental deposits has begun during this fracturing phase. The geological formations in our study area belong to four major lithological and structural units: the Archean basement of the Ntem Complex, the Paleoproterozoic rocks of the Nyong unit, the Neoproterozoic cover, and the Cretaceous sedimentary formations [13] (Figure 1). The Archean basement is mainly made up of greenstones, charnockite, and high-K granites [14]. The Nyong unit is formed following the remobilization of Archean basement rocks from the Ntem Complex. This remobilization happened after the collision 
between the Congo Craton and São Francisco plate. There are rocks like gneiss or schist with some granitoid intrusions. Cretaceous rocks also cover the study area like sandstone, limestone, and shale [15].

Previous studies have shown that the study area has undergone compression and stretching tectonics, thus giving rise to a fault system [16]. For example, we have the KribiCampo fault (KCF), an extension of the Sanaga fault [15, 17]. The KCF would also be linked to the Kribi shear zone formed during the breakup of Gondwana $[18,19]$.

\section{Data and Method}

3.1. Terrestrial Gravity Data. The terrestrial gravity data used in this work come from a series of campaigns organized in Cameroon between 1963 and 1990 by ORSTOM (Office de la Recherche Scientifique et Technique d'Outre-Mer). These ground gravity data were referenced in [20], completed later by surveys (Princeton University in 1968, University of Leeds in 1982, and IRGM and University of Leeds between 1984 and 1988). Our study area contains 82 data points unevenly distributed with an average step ranging from 4 to $5 \mathrm{~km}$ (Figure 2). Our study area only includes terrestrial gravity data due to the difficulty of accessing data at sea. The coordinates of gravity stations have maximum error ranging between 200 and $2000 \mathrm{~m}$. The mean accuracy of gravity measurements is $0.2 \mathrm{mGal}$. The gaps observed in the spatial distribution of the ground gravity data are mainly due to the difficulty of access to some risky areas. Lacoste and Romberg gravimeters (model G, Nos. 471 and 828) have been used during the data collection. The gravimetric measurements have been corrected from effects due to earth tide and instrumental drift. Bouguer anomalies are obtained by applying Bouguer reductions to free air anomalies considering an average density of $2.67 \mathrm{~g} / \mathrm{cm}^{3}$.

The Bouguer anomaly map of our study area (Figure 2 ) is obtained after interpolation using the minimum curvature gridding algorithm. The interpolation has been performed by using the Oasis Montaj software with a grid size of $0.016^{0} \times 0.016^{0}$. We got a minimum of $-73.76 \mathrm{mGal}$ and a maximum of $28.21 \mathrm{mGal}$.

3.2. Satellite Gravity Data (EGM2008). The satellite gravity data are derived from the Earth Gravitational Model EGM2008 [21, 22]. The EGM2008 model was released by the U.S. National Geospatial-Intelligence Agency (NGA) EGM Development Team. This geopotential model contains spherical harmonic coefficients up to degree and order 2159, and some additional coefficients extend up to degree 2190 and order 2160. The model EGM2008 presents a complete database with a good resolution $\left(2.5^{\prime} \times 2.5^{\prime}\right)$. It contains terrestrial, marine, airborne, and satellite gravity data. Unlike terrestrial gravity data, satellite gravity data are available in areas difficult to reach and could solve poor resolution and sparseness of terrestrial gravity data. Some researchers have validated this gravity database by comparing the results of their studies with those obtained from other sources of geophysical data [23-26]. These authors have suggested that gravity data derived from the EGM2008 model can fill the lack of terrestrial gravity data in some areas. Moreover, gravity models (EGM2008, EIGEN6C4, GECO, etc.) have already shown their performance in many geophysical studies. In fact, satellite gravity data of GOCE has been utilized for geological appraisal of the Singhbhum-Orissa Craton, India [27]. High-resolution satellite gravity data of EGM2008 have been utilized for geological mapping of the Jharia coalfield [28]. The Bouguer anomalies of the EGM2008 model were obtained after applying topographic gravity corrections on free-air gravity data. The ETOPO1 digital terrain model [29] and a crustal density of $2670 \mathrm{~kg} / \mathrm{m}^{3}$ were used to compute these corrections. Figure 3 presents the Bouguer anomaly map derived from the EGM2008 model. The interpolation method used is the minimum curvature with a grid size of $0.0166^{\circ}$ (about $1.8 \mathrm{~km}$ ).

3.3. Method. The methodology adopted in this work begins with the use of the least square collocation technique to combine the two gravity databases (terrestrial and satellite). Then, to characterize Cameroon's southwestern coastal region, we have used the following methods: power spectrum analysis, regional/residual separation, horizontal gradient, and Euler deconvolution.

3.3.1. Least Square Collocation. The least square collocation technique [30] is used in this work to combine terrestrial gravity data with the EGM2008 satellite gravimetric model. It is a statistical estimation technique combining least square adjustment and least square prediction into a linear regression model. To apply this technique, terrestrial gravity data are first used to bring out the short wavelengths of the gravity field by evaluating their differences with the gravimetric grid derived from the EGM2008 model. Then, the GEOGRID program of the GRAVSOFT package [31] is used to interpolate these differences on a regular grid, with the same resolution as the EGM2008 model. During this processing, the second-order Markov covariance model was applied with the following parameters: a correlation length of $30 \mathrm{~km}$ and $1 \mathrm{mGal}$ of white noise. The model parameters have been optimized by testing them in a range of $10-50 \mathrm{~km}$ and $1-5 \mathrm{mGal}$.

$$
c(s)=c_{0}(1+\alpha s) e^{-\alpha s},
$$

where $c_{0}$ is obtained automatically from the data, $\alpha$ is determined from the correlation length, and $s$ represents the distance between the pair of points considered.

The residual grid obtained is finally added to that of the gravity data derived from the EGM2008 model to increase the latter's accuracy at high frequencies. This method has been already successfully used to combine marine gravity data with altimetric models [32].

3.3.2. Power Spectrum Analysis. The power spectrum analysis is commonly used in geophysics to assess the depth of gravity anomaly sources present in the lithosphere [33-35]. The power spectrum of one or more anomalous sources can be obtained by carefully choosing a grid on which we want to determine the different depths of anomalous sources. The determination of the average depth of density contrasts 


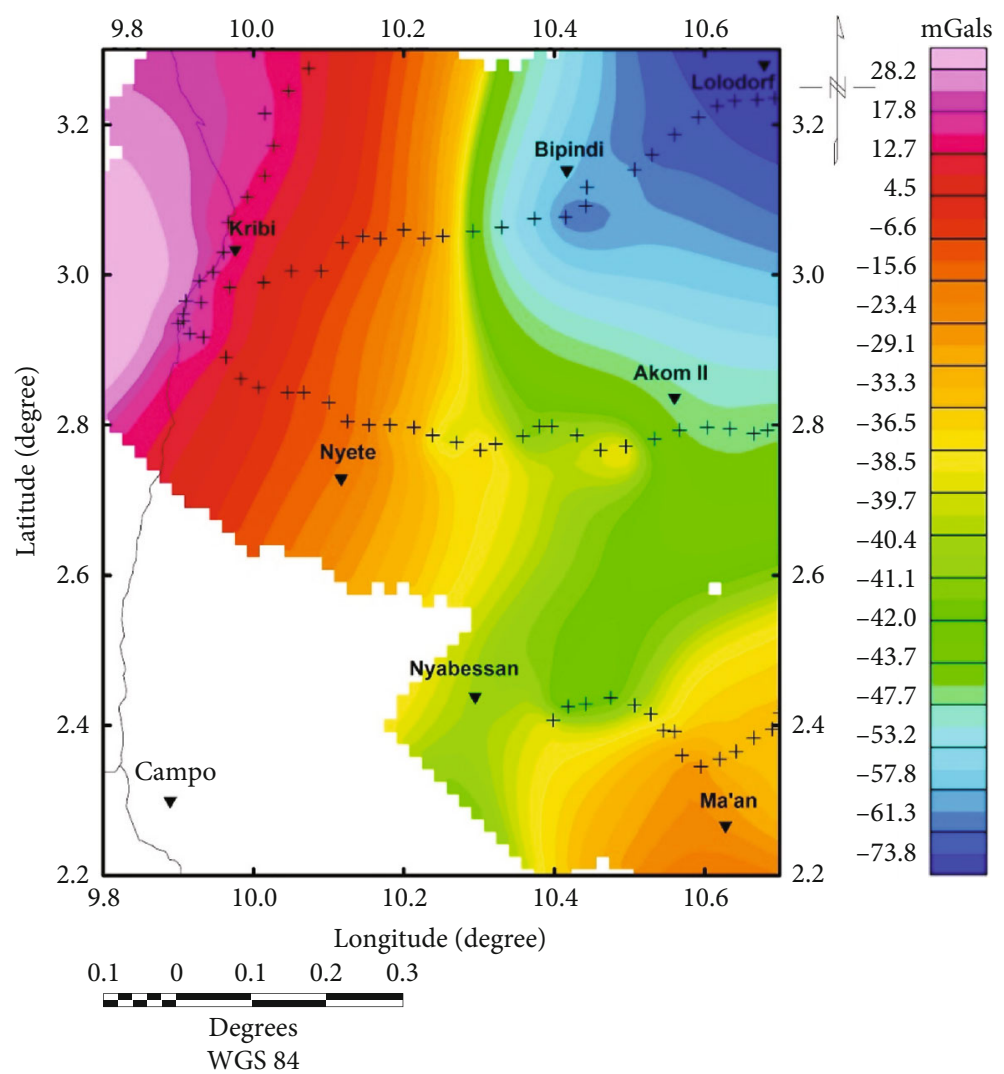

FIGURE 2: Distribution of gravity data and Bouguer anomaly map of the study area. The gravity data are recorded by stations represented here by black crosses.

inside the crust depends on the size of the target area. The area size should be at least three or four times larger than the depth that needs to be determined [36].

In this work, we used this method to perform a regional/residual separation and to determine the different sediment thicknesses present in the coastal region. Once the power spectrum is calculated, its logarithm must be represented on a graph as a function of radial frequency. The following formula gives the depth of the different anomalous sources:

$$
h=\frac{\Delta \log E}{4 \pi \Delta k},
$$

where $E$ is the power spectrum, $k$ is the wavelength in cycles $/ \mathrm{km}$, and $h$ is the depth in $\mathrm{km}$.

3.3.3. Regional/Residual Separation. The Bouguer anomaly can be divided into a short-wavelength component (residual anomaly) corresponding to the gravity signal caused by shallow structures and a long-wavelength component (regional anomaly) corresponding to the gravity signal of deep and large structures. To make a good assessment of the sediment depth to the basement, the low frequencies of deep and large sources must be subtracted from the Bouguer anomaly map. There are several regional/residual separation methods in the literature [37-39]. The upward continuation method was used to perform this regional/residual separation. This is a good filtering technique to separate regional anomalies due to deep sources. Regional/residual separation using the upward continuation method consists of choosing a depth to highlight regional anomalies; the average separation depth of regional and residual anomalies can be determined using spectral analysis. The residual anomalies are then deduced by subtracting the regional anomalies from the Bouguer anomalies.

3.3.4. Horizontal Gradient/Upward Continuation. Also called total horizontal derivative, the horizontal gradient is a good technique to delineate structural features inside the lithospheric crust [26]. The local horizontal gradient maxima of a gravity field highlight the different geological contacts and lineaments of a given area [40, 41]. This method has the advantage of being more stable when some noises appear in the gravity field. For a gravity field $G(x, y)$, the horizontal gradient magnitude (HGM) is given by the following formula [42]:

$$
\mathrm{HGM}=\sqrt{\left(\frac{\partial G}{\partial x}\right)^{2}+\left(\frac{\partial G}{\partial y}\right)^{2}}
$$

To locate and determine the gravity sources, many edge detection techniques are available. In this study, we have used the horizontal gradient method because this technique is commonly considered for the edge detection using gravity 


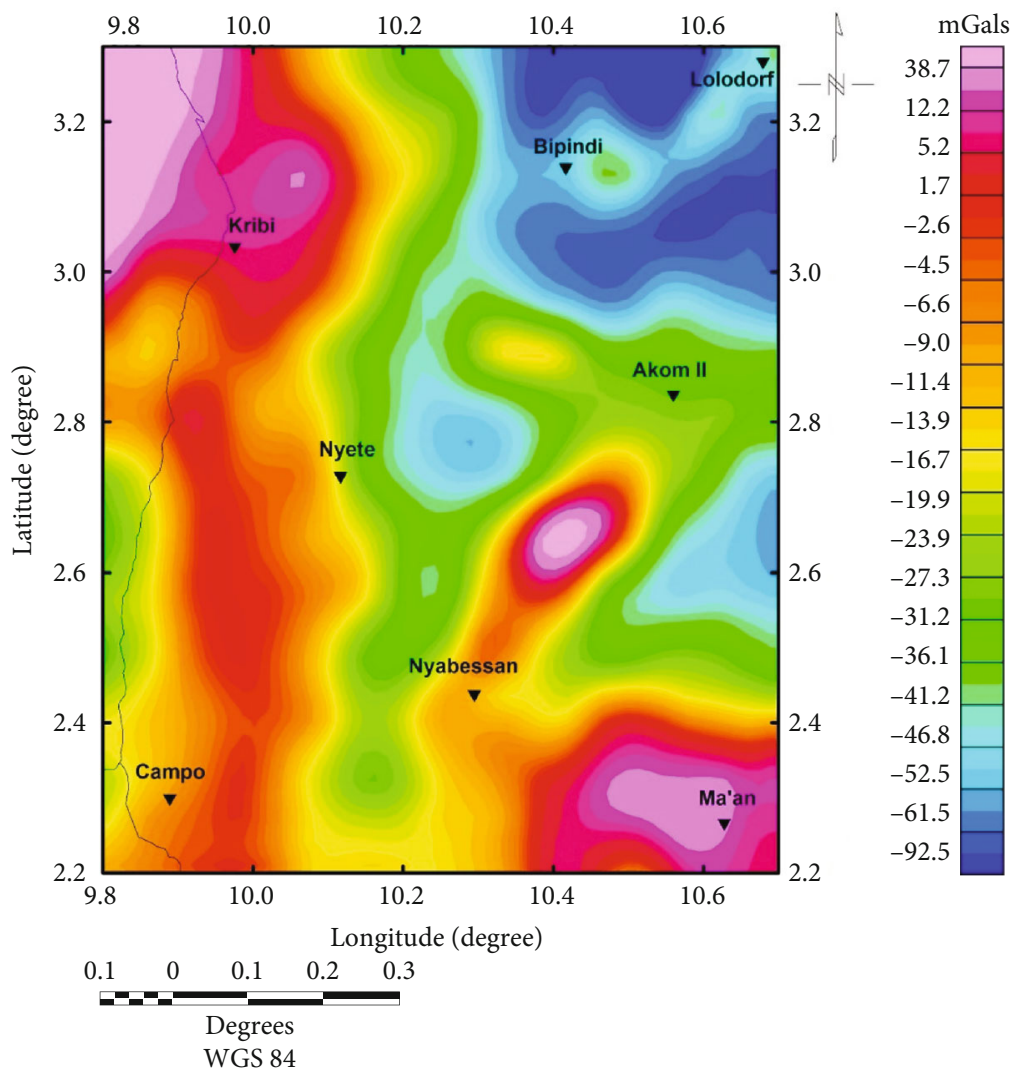

Figure 3: Bouguer anomaly map of the study area derived from the EGM2008 model.

TABLE 1: Statistics of the differences between terrestrial gravity data and gravity data from the EGM2008 model before and after combination by LSC (unit: $\mathrm{mGal}$ ).

\begin{tabular}{lcccc}
\hline & Min & Max & Mean & STD \\
\hline Before LSC & -36.41 & 21.92 & -5.27 & 15.96 \\
After LSC & -3.65 & 1.61 & -0.04 & 1.01 \\
\hline
\end{tabular}

data and it also enhances both deep and shallow depth lineaments [26].

The upward continuation technique is a stable computation at higher heights, which is influenced by the larger and deeper sources and reduces the higher-frequency components associated with possible shallow surface noise. The upward continuation approach provides better imaging of regional features by suppressing the effect of shallow surface noises [42]. Upward continuation enhances long-wavelength deep-seated regional features while suppressing highfrequency features. The resulting gravity field from an upward continuation level of $Z$ retains anomalies from sources below a depth of $Z_{0}=Z / 2$, whereas sources above are more attenuated $[38,43]$. Nevertheless, the decision on the appropriate continuation height is generally decided through inspection by comparing results from a range of heights.

The location of maxima of horizontal gradient magnitude can be simply identified by visual inspection. So the combination of the horizontal gradient maxima and upward continuation technique is generally used to highlight the different lineaments and their dip (vertical or oblique). This technique consists of producing several upward continued maps at increasing heights and applying a horizontal gradient to these maps. The superposition of each upward continued map maxima allows a better evaluation of lineament orientation [42].

3.3.5. Euler's Deconvolution. Euler's deconvolution is used to determine the position and apparent depth of gravimetric sources or magnetic anomalies $[36,44]$. This method consists of linking gravity field components and position of anomalous sources with a degree of homogeneity called "structural index." Euler's deconvolution equation [44] is written as follows:

$$
\left(x-x_{0}\right) \frac{\partial g}{\partial x}+\left(y-y_{0}\right) \frac{\partial g}{\partial y}+\left(z-z_{0}\right) \frac{\partial g}{\partial z}=-N(B-g)
$$

where $\left(x_{0}, y_{0}, z_{0}\right)$ are the coordinates of the gravity anomaly source $g(x, y, z), N$ is the structural index which represents the measure of the gravity field rate decreasing with the distance from the source, and $B$ is the regional gravity field.

In geology, the depths obtained by Euler's deconvolution method represent the stratigraphic or structural transitions encountered in geological formations. These Euler solutions, therefore, appear where there are lithological discontinuities [26]. 


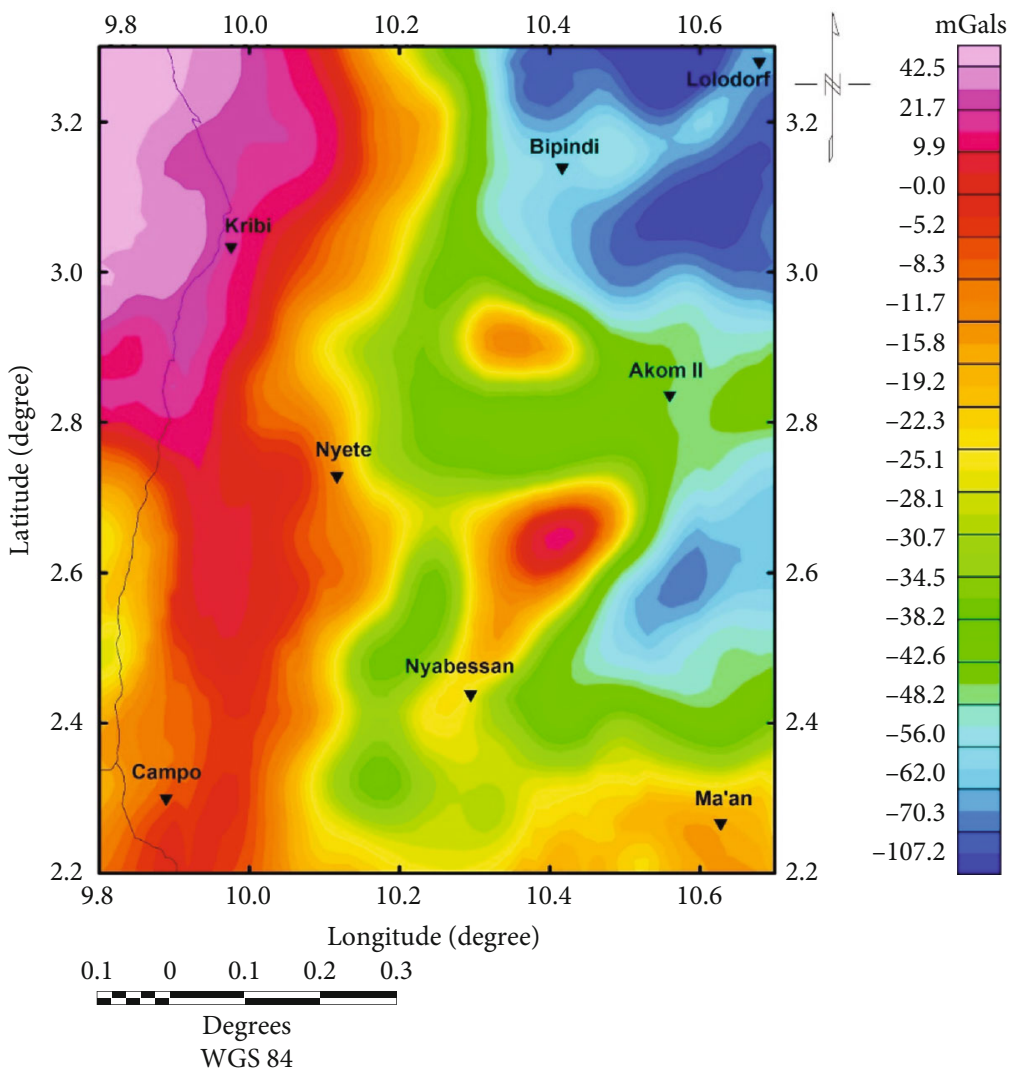

FIgURE 4: Combined Bouguer anomaly map in the study area.
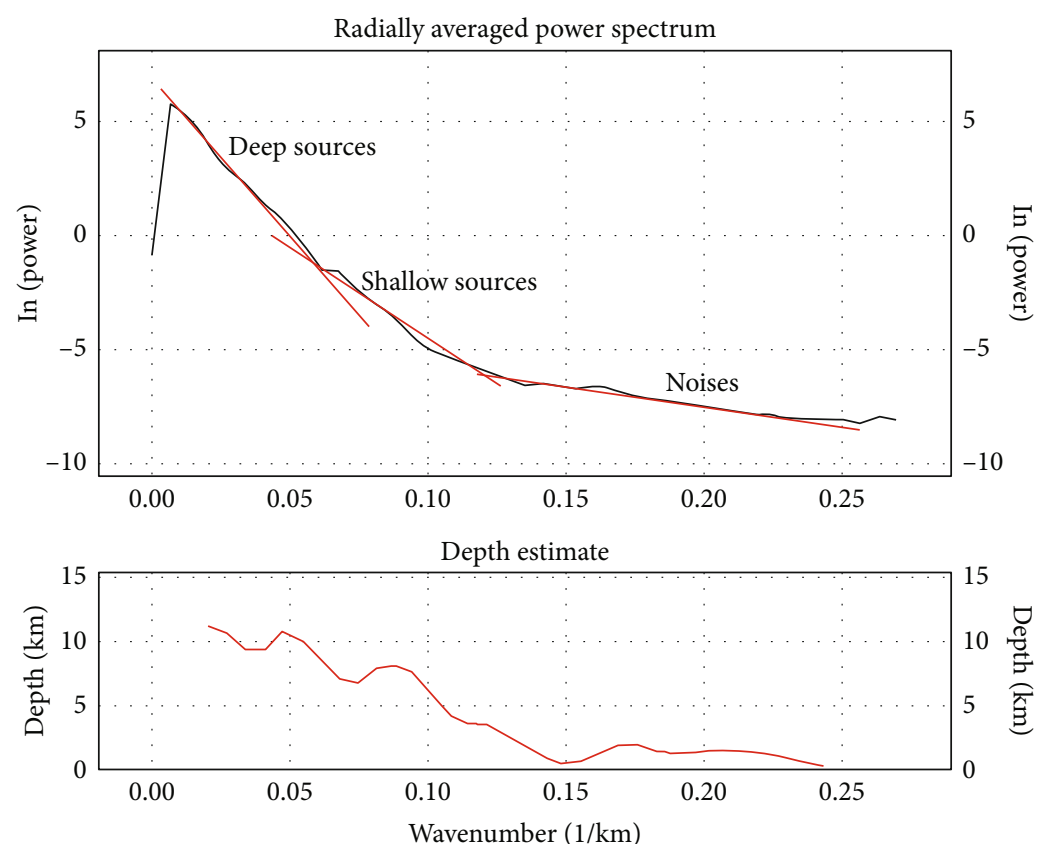

FIgURE 5: Power spectrum graph of Bouguer anomalies with two frequency domains.

\section{Results and Discussion}

4.1. Combination of Terrestrial and Satellite Gravity Data: Analysis and Interpretations. The least square collocation (LSC) has been applied in this work to combine terrestrial gravity data with satellite gravity data derived from the EGM2008 geopotential model. The comparison between terrestrial gravity data and satellite gravity data derived from the EGM2008 model before and after the LSC stage shows a significant improvement (Table 1). The combination of the two 


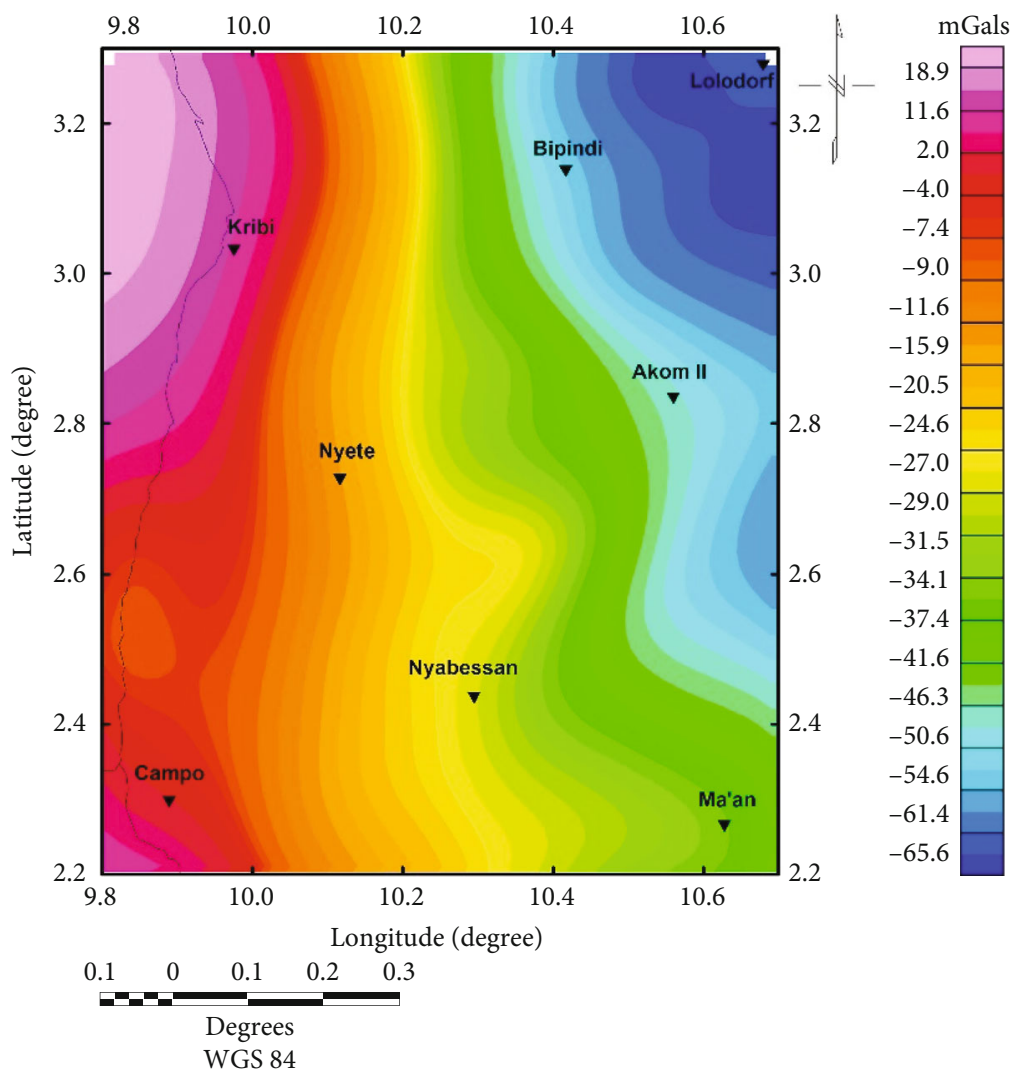

(a)

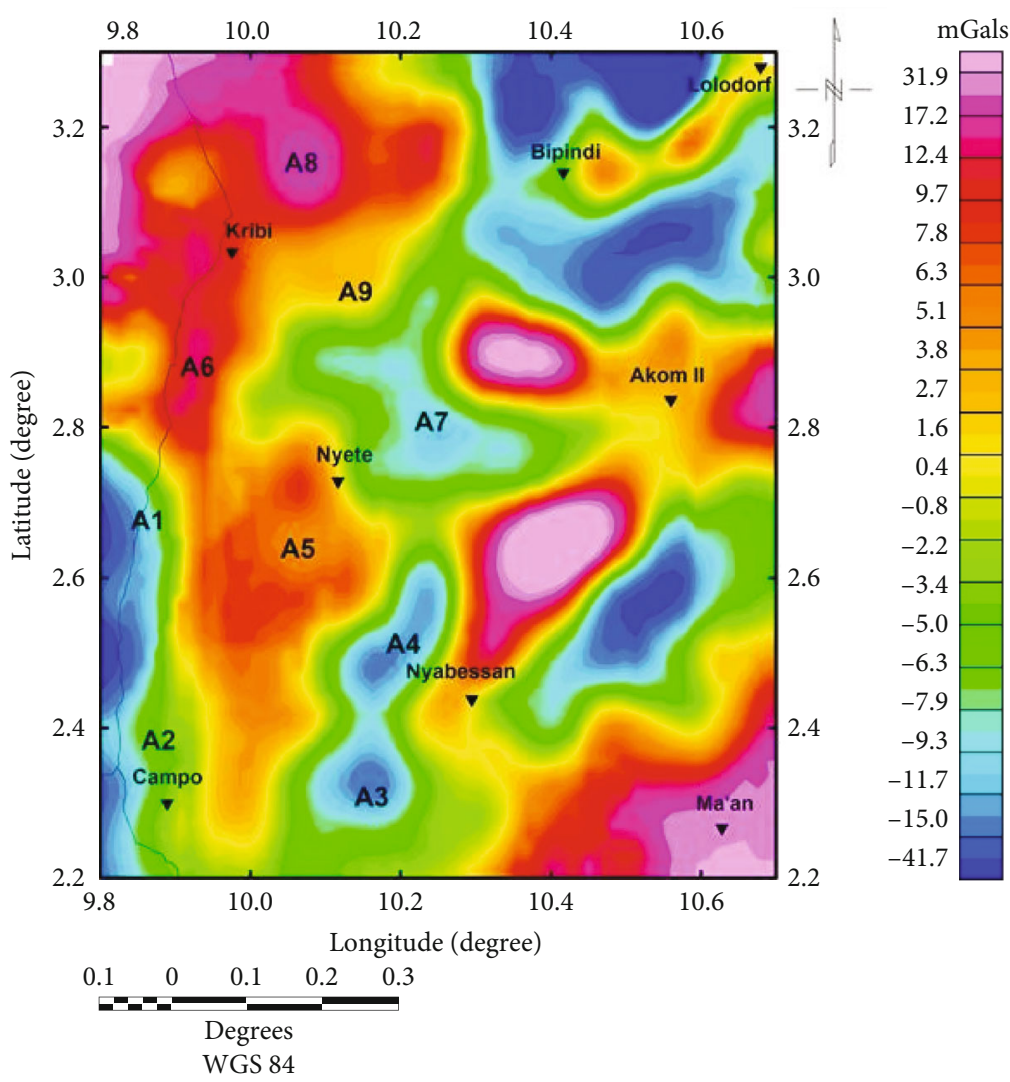

(b)

FIGURE 6: (a) Regional Bouguer anomaly map; (b) residual Bouguer anomaly map. 


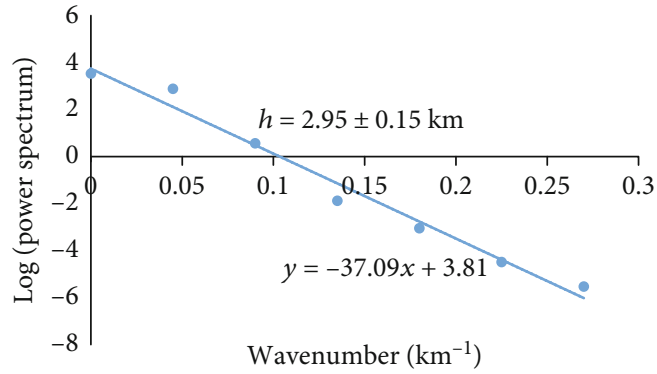

FIgURE 7: Power spectrum of gravity data of a local anomaly (A3). The average depth of the anomalous source is obtained from the slope of the linear curve.

TABle 2: Average thickness of sediment layers evaluated using the power spectrum of residual gravity anomalies.

\begin{tabular}{lc}
\hline Anomaly & Sediment thickness $(\mathrm{km})$ \\
\hline A1 & $1.68 \pm 0.08$ \\
A2 & $2.24 \pm 0.11$ \\
A3 & $2.95 \pm 0.15$ \\
A4 & $2.79 \pm 0.14$ \\
A5 & $2.81 \pm 0.14$ \\
A6 & $2.42 \pm 0.12$ \\
A7 & $2.20 \pm 0.11$ \\
A8 & $2.95 \pm 0.15$ \\
A9 & $2.79 \pm 0.14$ \\
\hline
\end{tabular}

databases (terrestrial and satellite) comes to produce a new gravity model more realistic. The mean and standard deviation of the differences have dropped from -5.27 to $-0.04 \mathrm{mGal}$ and 15.96 to $1.01 \mathrm{mGal}$, respectively. The main differences observed between terrestrial gravity data and the EGM2008 model before the LSC stage are their different spectral contents. The EGM2008 model has a poor representation of the short wavelengths of the earth's gravity field while the terrestrial gravity data has a full spectrum. So terrestrial gravity data contains all the possible wavelengths of the earth's gravity field.

Figure 4 shows the combined Bouguer anomaly map. This map is obtained from the interpolation of combined terrestrial and satellite gravity data. The interpolation was carried out by applying the Krigeage algorithm using the Oasis Montaj software. The Bouguer anomaly map (Figure 4) shows values ranging from -107.2 to $42.5 \mathrm{mGal}$. This map reflects the lateral density changes in the subsurface of the study area.

The Bouguer anomaly map (Figure 4) shows gravity signatures decreasing from west to east on the study area. Relatively positive gravity anomalies largely dominate the western part. These positive anomalies could be due to a shallow crystalline basement and an uplift of mantle formations. The geological work of [45] has shown that this part of the study area had known significant magmatic activities during the opening of the central African rift. In the eastern part of the study area, we observe negative anomalies going up to a minimum of $-107 \mathrm{mGal}$. These low-density anomalies could be due to a subsidence of the basement rock with lowdensity granitic intrusions in the north of the Congo Craton [17]. In general, the combination of the two gravity databases (in situ and satellite) presents several signatures almost identical to those observed in the work of $[3,4]$. However, our Bouguer anomaly map reveals significant new signatures, particularly in areas with a lack of terrestrial gravity data. We note the presence of a positive local anomaly located in the northern part of the Nyabessan locality. This highamplitude anomaly is probably due to the presence of a high-density intrusive body. In the north of the Ma'an locality, we can also observe a local anomaly of very small amplitude.

We have proceeded to the separation of residual anomalies from the regional field for a better interpretation of the Bouguer anomalies with the variation of shallow and deep formations. The average separation height of regional and residual anomalies has been determined by spectral analysis using the Oasis Montaj software. Figure 5 shows the power spectrum graph. This graph is used to separate deep sources from shallow ones. A depth of $10 \mathrm{~km}$ has been estimated as being the level at which we find deep sources. We applied a filter (upward continuation) on the Bouguer anomaly map at the depth $h=10 \mathrm{~km}$ to isolate the regional gravimetric signatures from the residual one.

The regional anomaly map (Figure 6(a)) shows a strong gravity gradient in the $\mathrm{W}$-E direction over the study area. Regional anomalies have a maximum intensity of $16.9 \mathrm{mGal}$ in the west and gradually decrease towards the east to reach a minimum value of $-65.6 \mathrm{mGal}$. These regional variations of density are mainly due to a progressive thinning of the lithospheric crust in direction through the coast. This assertion fits well with the work of [4] which shows the mafic interface depth of the study area. This work revealed that the minimum depths are encountered in the western part $(15.6-17 \mathrm{~km})$, and they are gradually increasing towards the east of the study area.

The residual map (Figure 6(b)) shows several local anomalies. The peaks of positive anomalies observed in the northeast of the Nyabessan locality and around Akom II would be caused by intrusions of magmatic rocks inside the basement rock. On the western part of the residual map, the positive signature would be caused by a basement upwelling. Near the Kribi area, there might be an intrusion of high-density material below the sedimentary cover. This assertion corroborates with the work of [46], which shows that the positive Kribi anomaly is due to the presence of an intrusive igneous body of approximate density $2.74 \mathrm{~g} / \mathrm{cm}^{3}$. Negative signatures also characterize the residual anomaly map. Compared to the geological map (Figure 1), the negative anomalies observed in the southwest of the study area reflect the Cretaceous sedimentary cover. A study [47] hypothesized that the negative signatures around Bipindi would be caused by a lowdensity intrusive block $\left(-0.095 \mathrm{~g} / \mathrm{cm}^{3}\right)$.

4.2. Estimation of Sediment Thickness. The spectral analysis was applied to a series of grids centered on local anomalies 


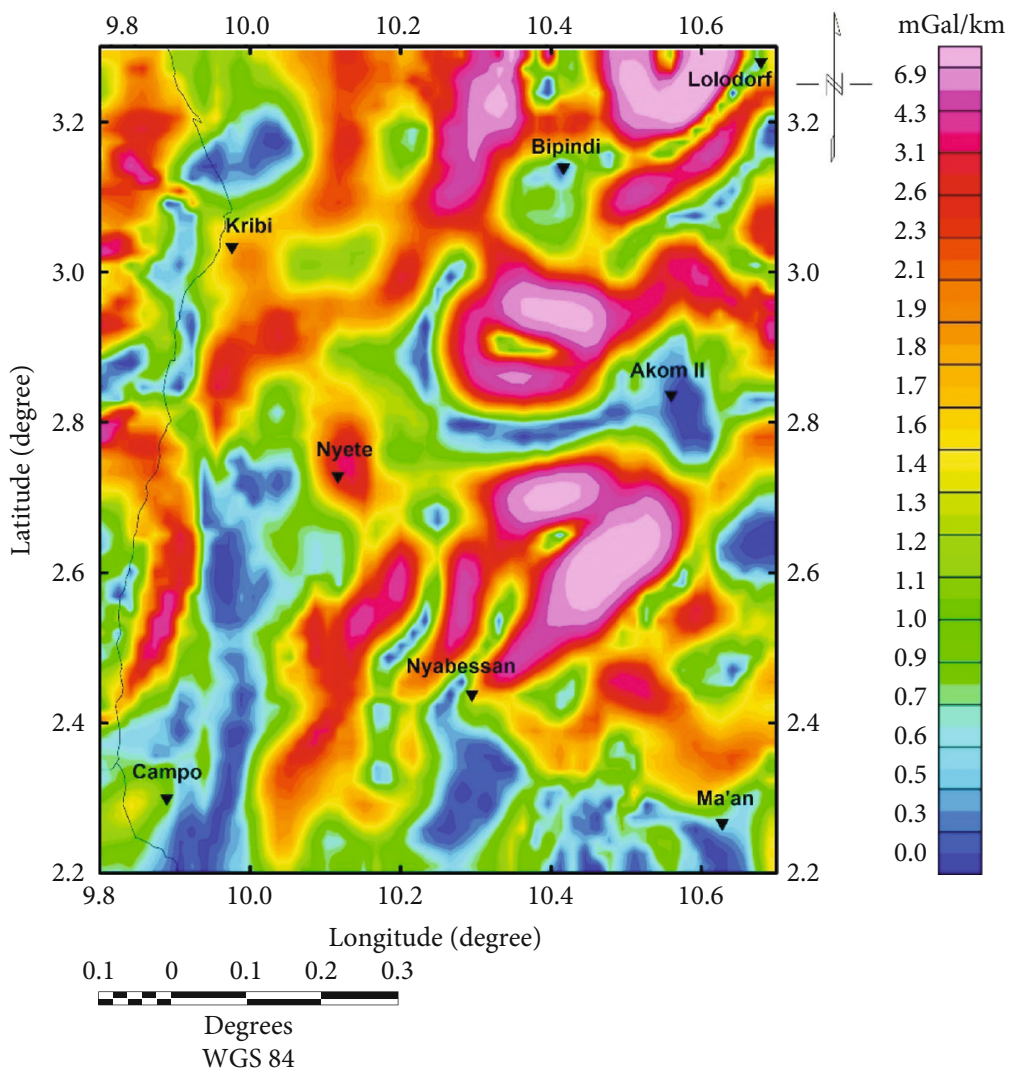

FIgURE 8: Map of the horizontal gradient of Bouguer gravity anomalies.

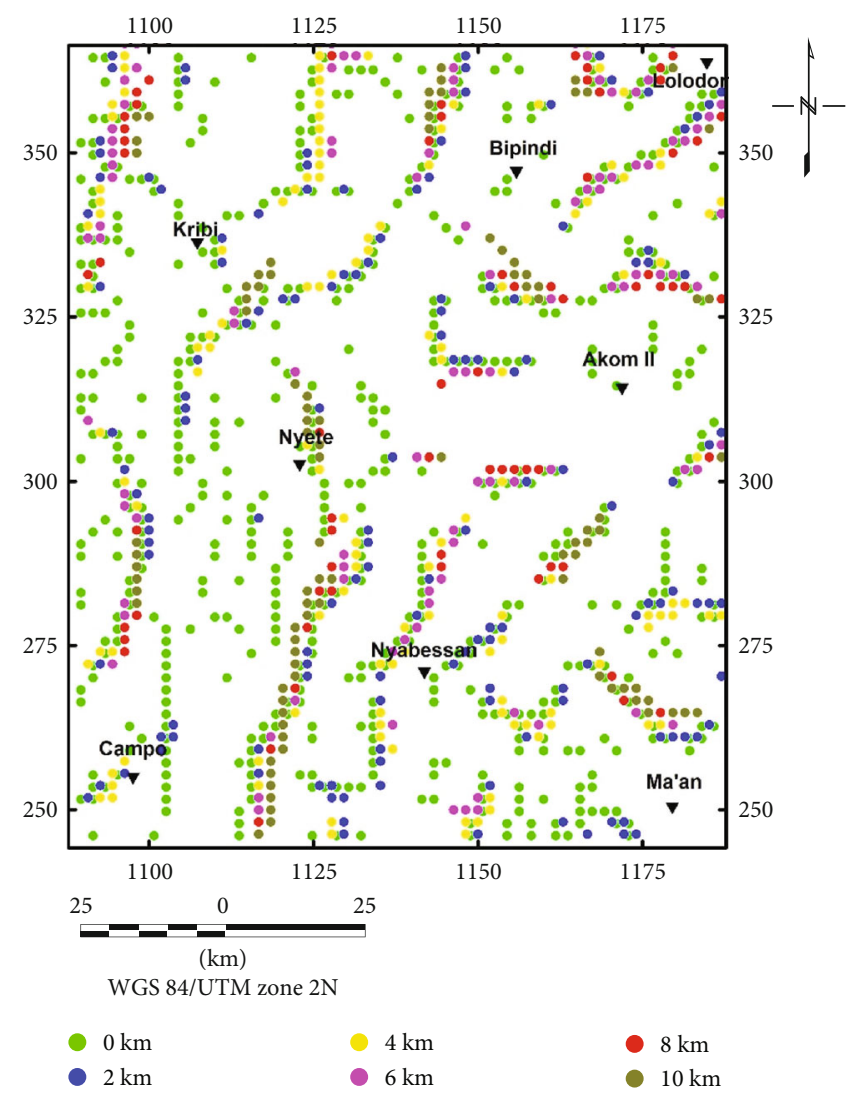

FIgURE 9: Maximum of the horizontal gradient of the Bouguer anomaly map and its upward continuation at different depths. 


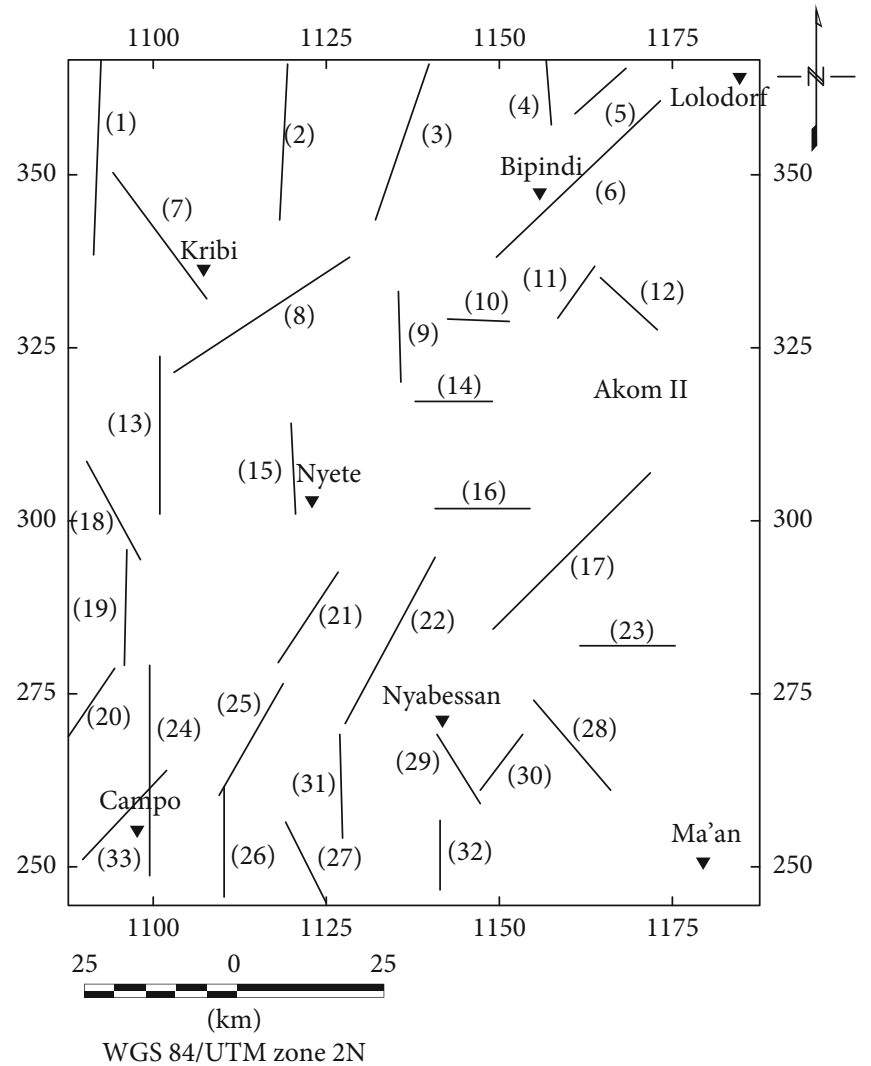

Figure 10: Lineament map of the southwestern coastal region of Cameroon.

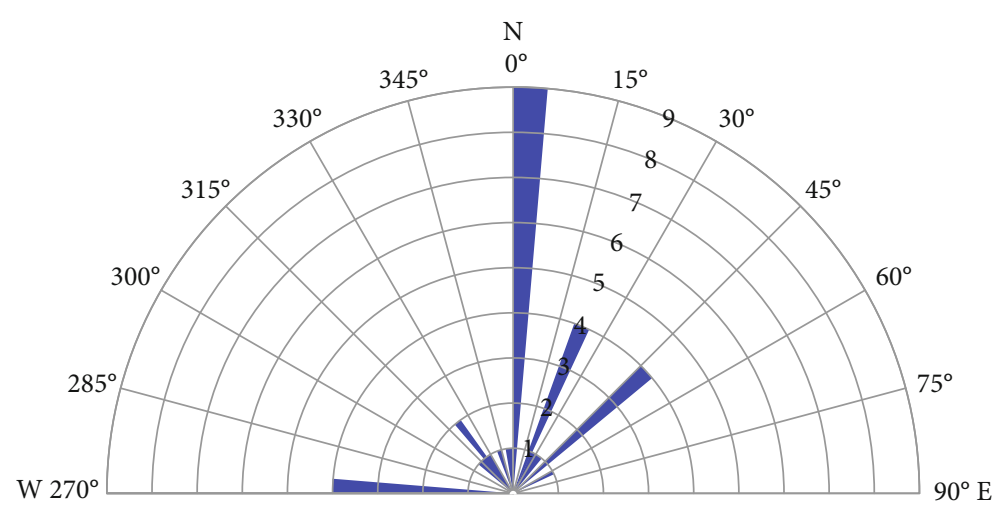

FIgURE 11: Rose diagram giving the direction of major faults and lineaments.

of the study area (A1, A2, A3, A4, A5, A6, A7, A8, and A9). This allows us to estimate the different thicknesses of the sediment cover on the study area.

Figure 7 shows a sample of the power spectrum curve varying with wavelength. The linear curve is obtained by applying the least square adjustment on the data points. The slope of the linear curve is used to assess the average depth of the bedrock, i.e., the thickness of the sediment layers. The sediment thicknesses were evaluated for each local anomaly grid in Figure 6(b) and are presented in Table 2. The table shows us that the western part of the southwestern coastal region of Cameroon abounds with a great quantity of sediment. The thicknesses vary moderately between $1.68 \pm 0.08$ and $2.95 \pm 0.15 \mathrm{~km}$. The error values have been obtained by considering that each one is representing $5 \%$ of the mean depth value of the basin [48]. The western part of the study area is covered with a sediment layer of practically uniform thickness. The most promising areas for further investigation are located around the A3, A4, A5, A8, and A9 anomalies.

These results are important because they provide additional information for new oil and gas explorations in the study area.

\subsection{Structural Characterization of the Basin}

4.3.1. Horizontal Gradient. We have calculated the horizontal gradient amplitudes of Bouguer anomalies to bring out 
discontinuities areas or density contrasts that exist in the basement. These amplitudes were calculated in the frequency domain using the Oasis Montaj software. The horizontal gradient map presented in Figure 8 shows some areas with a large density variation. These areas can represent faults, geological contacts, or intrusive formations.

The horizontal gradient map (Figure 8) highlights several areas of the strong gradient with different shapes and directions. These high-gradient areas are due to the major geological features underlying the basin (faults, fractures, intrusion of a rock density, or thinning of the crust). We observe maximum amplitudes of the horizontal gradient trending at the west of our study area in an N-S direction in general. By comparing the horizontal gradient map and the geological map (Figure 1), we notice a good correlation between several maximum amplitudes of the horizontal gradient map and some major faults of the study area. We also note that the high anomaly gradients have rather large extensions. These large extensions show that the geological contacts underlying the study area are not vertical and are relatively deep. The horizontal gradient zone observed around the locality of Bipindi is probably caused by the density contrast between a lowdensity intrusive block [47] and surrounding metamorphic formations.

In sum, the interpretation of this map helps to testify that the southwestern coastal region of Cameroon has been undoubtedly affected by intense tectonic activities at the level of its basement rock. This tectonics is justified by the presence of several zones of high gradients, signatures of several faults, and deep fractures. This shows that the sites rich in gas and oil are controlled by a deep tectonic.

\subsubsection{Determination of Lineament Using Horizontal Gradient} Maxima. We have applied a multiscale analysis on the Bouguer gravity anomalies to bring out the several faults and lineaments in our study area. The Bouguer anomalies were upward continued at different heights $(2,4,6,8$, and 10 $\mathrm{km})$. The horizontal gradient maxima of each continued upward map were then calculated and superimposed (Figure 9). The map of horizontal gradient maxima highlights areas of abrupt density changes. The coupling of the horizontal gradient maximum map to the continued upward maps computed at higher heights shows the vertical extension of the different anomalous structures. The quasilinear arrangement of several maxima would correspond to the signature of a fault or a geological contact. In contrast, a quasicircular alignment of these maxima would correspond to the horizontal limit of an intrusive body [47].

From the map of the horizontal gradient maxima, we highlighted a lineament map of our study area (Figure 10). The rose diagram of all the lineaments identified in the study area is presented in Figure 11. The main directions of the lineaments are N-S, E-W, SW-NE, and SSW-NNE. But the N-S direction prevails on all the other lineaments. These results join the work of [2], which determined the major lineaments in the Kribi-Campo-Ma'an area with the following directions: N-S, SW-NE, E-W, NE-SW, and SSW-NNE. The major directions of lineaments are trending from N-S to SSW-NNE. These lineaments are probably related to the

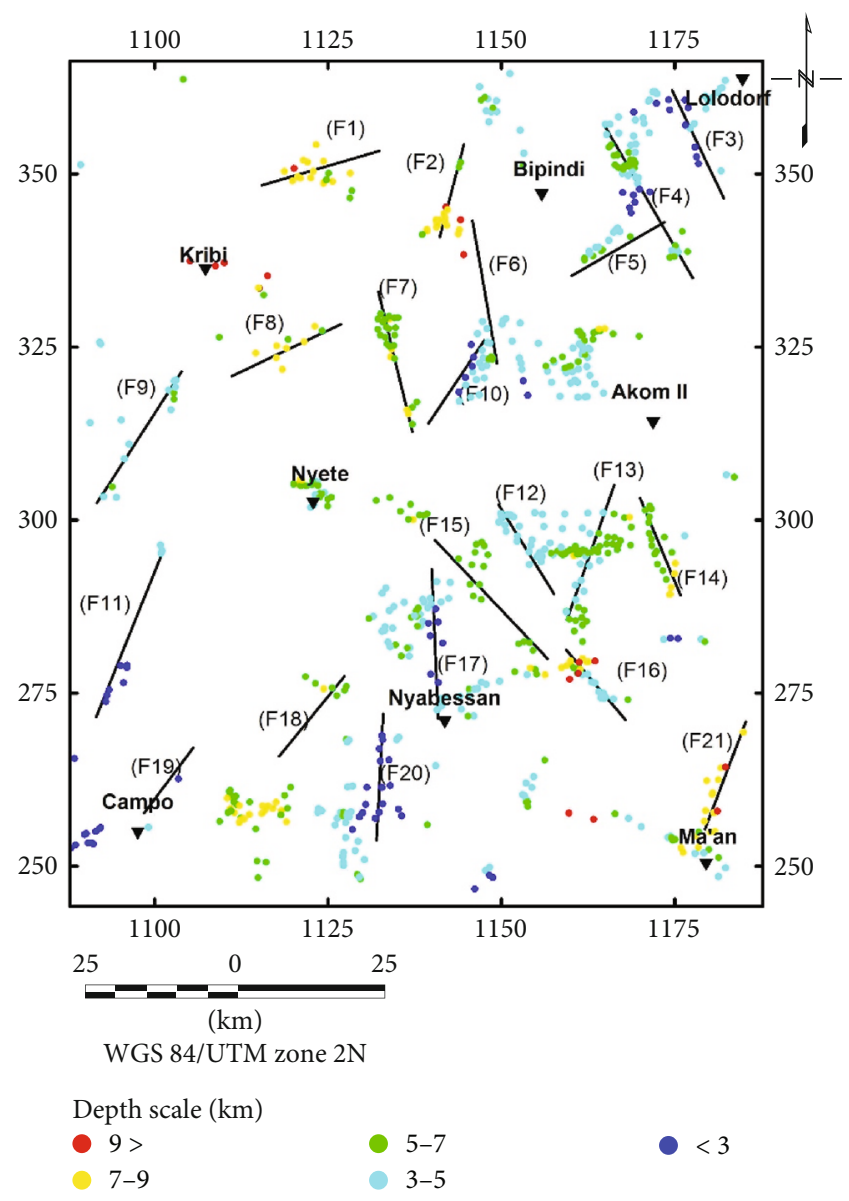

FiguRE 12: Structural interpretation of Euler solutions for $N=0.1$.

Kribi-Campo fault, which affects a large part of the study area. The Kribi-Campo fault is connected to the Kribi shear zone, highlighted by [15]. The E-W direction would be linked to the opening of the equatorial Atlantic Ocean. The faults trending in an SW-NE direction probably affected the bedrock during the collision between the Congo Craton and the Pan-African North-Equatorial Fold Belt $[49,50]$.

The lineaments and faults in the southwestern coastal region are an excellent factor for the migration of hydrocarbon resources. Understanding the circulation and formation of fluids in the study area can be easily elucidated by analyzing the structural map. Besides, the lineaments identified correlate strongly with the position of the faults represented on the geological map of our study area. This implies that our structural map of lineaments (Figure 11) could also help to update our study area's geological map.

\subsubsection{Solutions Obtained by the Euler Deconvolution Method.} The Euler deconvolution method was applied to the Bouguer anomalies with a window size $(W)$ of $5 \mathrm{~km} \times 5 \mathrm{~km}$, a maximum tolerance $(T)$ of 8 , and a structural index (SI) of 0.1 . In this study, different combinations of SI $(0,0.1,1$, and 2$)$, $W(5 \times 5,8 \times 8,10 \times 10$, and $15 \times 15), T(5 \%, 8 \%, 10 \%$, and $15 \%)$ have been analyzed, and the best clustering pattern is observed for contact with $\mathrm{SI}=0.1, W=10$, and $T=8$. Figure 12 presents structural solutions obtained by applying 
TABLE 3: Directions and depth of faults identified by the Euler deconvolution method.

\begin{tabular}{lcc}
\hline Fault ID & Direction & Depth range $(\mathrm{km})$ \\
\hline F1 & WSW-ENE & $>9$ \\
F2 & N-S & $>9$ \\
F3 & NNW-SSE & $3-5$ \\
F4 & NNW-SSE & $5-7$ \\
F5 & SW-NE & $7-9$ \\
F6 & N-S & $5-7$ \\
F7 & N-S & $7-9$ \\
F8 & SW-NE & $7-9$ \\
F9 & SSW-NNE & $5-7$ \\
F10 & SSW-NNE & $3-5$ \\
F11 & SSW-NNE & $<3$ \\
F12 & NE-SW & $3-5$ \\
F13 & SW-NE & $5-9$ \\
F14 & NW-SE & $5-7$ \\
F15 & NW-SE & $5-7$ \\
F16 & NW-SE & $3-5$ \\
F17 & N-S & $3-5$ \\
F18 & SW-NE & $5-7$ \\
F19 & SW-NE & $<3$ \\
F20 & N-S & $<3$ \\
F21 & SSW-NNE & $>9$ \\
\hline & &
\end{tabular}

the Euler deconvolution method on Bouguer anomalies. We note that the study area is affected by a system of superficial faults with a depth ranging from 3 to more than $9 \mathrm{~km}$. This explains why the origins of lineaments and faults in the study area are different. We also note that the most superficial faults are found in the south-east of the study area. The main faults affecting the southwestern coastal region of Cameroon, and their direction and depth, are presented in Table 3. The predominant faults are trending in N-S and SSW-NNE directions. These directions are correlated with those previously highlighted by the map of the horizontal gradient maxima. This information on the orientation of superficial faults is very important because it can help to determine the direction of circulation of fluids inside the sediment cover. The various faults identified in the study area would be the response of deep tectonic activities or intrusion of metamorphic rocks inside the sediment layers.

\section{Conclusion}

This paper was aimed at giving a new structural overview to the southwestern coastal region of Cameroon with the combination of two gravity databases (terrestrial and satellite). The combination of these two databases has been validated by the previous studies. However, our Bouguer anomaly map reveals new signatures, particularly the presence of a positive local anomaly situated at the north of the Nyabessan locality and a very small anomaly on the northern side of the Ma'an locality. The spectral analysis of the Bouguer anomaly residual map has been used to determine the thicknesses of the sediment cover present in some localities of the study area. It appears that the southwestern coastal region of Cameroon has a quasiuniform sediment cover on its western part (with thicknesses of sediments that vary moderately between $1.68 \pm 0.08$ and $2.95 \pm 0.15 \mathrm{~km})$. These results on the sediment cover of the study area could greatly contribute to the identification of sites with good hydrocarbon potential. To make a structural characterization of the study area, we have coupled the horizontal gradient method with the upward continuation technique.

We highlighted major lineaments with their different directions (N-S, E-W, SW-NE, and SSW-NNE). The N-S direction prevails over those of all the other lineaments. This major direction is undoubtedly linked to the Kribi shear zone. The Euler deconvolution method was applied to the Bouguer anomaly map to highlight the different surface faults in the study area and their depth. The majority of the surface faults are trending in N-S and SSW-NNE directions. These directions are correlated with those highlighted by the horizontal gradient maxima. The fault system identified in our study area could strongly control the architecture of the sediment cover and constitute structural traps useful for fluid accumulation. These lineaments and faults in the sediment layer or in the basement are excellent factors for the migration of hydrocarbon resources. Understanding the circulation and formation of fluids can easily be elucidated through the analysis of the structural map. Our structural map of lineaments could also help update the geological map of our study area.

Despite the precision brought by the combination of the two gravity databases (in situ and satellite), our study must be deepened to obtain more realistic results and to have a better knowledge of the structure of the study region. 2D seismic studies should be associated with the results of this study for a good geophysical overview of this region.

\section{Data Availability}

The Bureau Gravimetrique International (BGI) provided ground gravity data. The U.S. National GeospatialIntelligence Agency (NGA) EGM Development Team made the EGM2008 global gravity model available free of charge on its web page.

\section{Conflicts of Interest}

The authors declare that there is no conflict of interest.

\section{Acknowledgments}

The authors thank the Bureau Gravimetrique International (BGI) for providing ground gravity data over the study area. We also thank Professor René Forsberg who kindly gives us the GRAVSOFT package, which allowed us to realize the prediction of gravity data (GEOGRID program). The U.S. National Geospatial-Intelligence Agency (NGA) EGM Development Team is appreciated for making the EGM2008 global gravity model available free of charge on 
its web page. We are also grateful to the geodesy laboratory researchers of the National Institute of Cartography for their different comments and reviews, which have helped to improve this work.

\section{References}

[1] F. Koumetio, D. Njomo, C. T. Tabod, T. C. Noutchogwe, and E. Manguelle-Dicoum, "Structural interpretation of gravity anomalies from the Kribi-Edea zone, South Cameroon: a case study," Journal of Geophysics and Engineering, vol. 9, no. 6, pp. 664-673, 2012.

[2] O. A. M. L. Clotilde, C. T. Tabod, N. Séverin, K. J. Victor, and T. K. A. Pierre, "Delineation of lineaments in South Cameroon (Central Africa) using gravity data," Open Journal of Geology, vol. 3, no. 5, pp. 331-339, 2013.

[3] K. P. R. Malquaire, O. A. M. L. Clotilde, N. Nfor, N. M. Théophile, and M. D. Eliezer, "Determination of structural and geometrical parameters of the Kribi-Campo sedimentary subbasin using gravity data," International Journal of Geosciences, vol. 8, no. 9, pp. 1210-1224, 2017.

[4] S. Nguiya, W. Lemotio, P. Njandjock Nouck, M. M. Pemi, K. A. Tokam, and E. Ngatchou, "3D mafic topography of the transition zone between the north-western boundary of the Congo Craton and the Kribi-Campo sedimentary basin from gravity inversion," International Journal of Geophysics, vol. 2019, Article ID 7982562, 15 pages, 2019.

[5] J. J. Nguimbous-Kouoh, J. Tchutchoua, S. Ngos III, T. N. Mbarga, and E. Manguelle-Dicoum, "Hydrocarbon potential of two coastal basins (Cameroon)," International Journal of Geosciences, vol. 9, no. 2, pp. 131-147, 2018.

[6] J. Kamguia, E. Manguelle-Dicoum, C. T. Tabod, and J. M. Tadjou, "Geological models deduced from gravity data in the Garoua basin, Cameroon," Journal of Geophysics and Engineering, vol. 2, no. 2, pp. 147-152, 2005.

[7] T. Ndougsa-Mbarga, E. Manguelle-Dicoum, and J. O. Campos-Enriquez, "Gravity anomalies, sub-surface structure and oil and gas migration in the Mamfe, Cameroon-Nigeria, sedimentary basin," Geofísica Internacional, vol. 46, no. 2, pp. 129-139, 2007.

[8] N. Nfor, O. Angue Marie Louise Clotilde, K. Petou Rokis Malquaire, M. D. Eliezer, L. Tsakou Julyo Achille, and P. Kwagag Jöel, "A comparative geophysical study of the sedimentarymetamorphic contacts in the Douala and Kribi-Campo subbasins of Cameroon," Trends Journal of Sciences Research, vol. 3, no. 1, pp. 33-51, 2018.

[9] Y. N. Shandini, P. A. Kouske, S. Nguiya, and M. P. Marcelin, "Structural setting of the Koum sedimentary basin (North Cameroon) derived from EGM2008 gravity field interpretation," Contributions to Geophysics and Geodesy, vol. 48, no. 4, pp. 281-298, 2018.

[10] T. Gruber, "Evaluation of the EGM2008 gravity field by means of GPS levelling and sea surface topography solutions," Publication the International Association of Geodesy and International Gravity Field Service, vol. 4, pp. 3-17, 2009.

[11] W. Torge, Geodesy, Walter de Gruyte, Berlin, 3rd edition, 2001.

[12] K. Burke, T. F. J. Dessauvagie, and A. J. Whiteman, "Opening of the gulf of Guinea and geological history of the Benue Depression and Niger delta," Nature Physical Science, vol. 233, no. 38, pp. 51-55, 1971.
[13] D. Minyem and A. Nedelec, "Origin and evolution of the Eseka gneisses (Cameroon): Archean TTG reworked in the Panafrican mobile belt," in 15th Colloquium of African Geology, pp. 21-24, Université Nancy I, France, 1990.

[14] J. P. Nzenti, T. Njanko, E. L. T. Njiosseu, and F. M. Tchoua, "Les domaines granulitiques de la chaîne panafricaine NordEquatoriale au Cameroun," Géologie et Environnement au Cameroun, vol. 1, pp. 255-264, 1998.

[15] M. L. C. O. Angue, S. Nguiya, R. Nouayou, A. P. T. Kamga, and E. Manguelle-Dicoum, "Geophysical investigation of the transition zone between the Congo Craton and the Kribi-Campo sedimentary basin (Southwestern Cameroon)," South African Journal of Geology, vol. 114, no. 2, pp. 145-158, 2011.

[16] J. M. Ntamak-Nida, S. Bourquin, J. C. Makong et al., "Sedimentology and sequence stratigraphy from outcrops of the Kribi-Campo sub- basin: Lower Mundeck Formation (Lower Cretaceous, southern Cameroon)," Journal of African Earth Sciences, vol. 58, no. 1, pp. 1-18, 2010.

[17] J. M. Tadjou, R. Nouayou, J. Kamguia, H. L. Kande, and E. Manguelle-Dicoum, "Gravity analysis of the boundary between the Congo Craton and the Pan-African belt of Cameroon," Austrian Journal of Earth Sciences, vol. 102, pp. 7179, 2009.

[18] K. Burke, "Seismic areas of the Guinea coast where Atlantic fracture zones reach Africa," Nature, vol. 222, no. 5194, pp. 655-657, 1969.

[19] L. Perez-Diaz and G. Eagles, "Constraining South Atlantic growth with seafloor spreading data," Tectonics, vol. 33, no. 9, pp. 1848-1873, 2014.

[20] F. Collignon, Gravimétrie et reconnaissance de la république fédérale du Cameroun, ORSTOM, Paris, 1968.

[21] N. K. Pavlis, S. A. Holmes, S. C. Kenyon, and J. K. Factor, “An earth gravitational model to degree 2160: EGM2008," in EGU General Assembly, pp. 13-18, Vienna, Austria, 2008.

[22] N. K. Pavlis, S. A. Holmes, S. C. Kenyon, and J. K. Factor, "The development and evaluation of the earth gravitational model 2008 (EGM2008)," Journal of Geophysical Research, vol. 117, no. B4, 2012.

[23] A. Eyike, C. S. Werner, J. Ebbing, and E. M. Dicoum, "On the use of global potential field models for regional interpretation of the West and Central African Rift System," Tectonophysics, vol. 492, no. 1-4, pp. 25-39, 2010.

[24] N. H. Evariste, L. Genyou, C. T. Tabod et al., "Crustal structure beneath Cameroon from EGM2008," Geodesy and Geodynamics, vol. 5, no. 1, pp. 1-10, 2014.

[25] J. Marcel, J. M. Abate Essi, P. N. Nouck, O. Sanda, and E. Manguelle-Dicoum, "Validation of gravity data from the geopotential field model for subsurface investigation of the Cameroon volcanic line (Western Africa)," Earth, Planets and Space, vol. 70, no. 1, 2018.

[26] P. G. Kamto, G. J. Nkoungou, S. C. Tchato, W. Lemotio, L. A. A. Atangana, and J. Kamguia, "Contribution of satellite gravity data (EGM2008) for structural characterization of the Goulfey-Tourba basin (Northern Cameroon)," The International Journal of Engineering and Science, vol. 9, no. 4, pp. 17, 2020.

[27] S. K. Pal and T. J. Majumdar, "Geological appraisal over the Singhbhum-Orissa Craton, India using GOCE, EIGEN6-C2 and in situ gravity data," International Journal of Applied Earth Observation and Geoinformation, vol. 35, pp. 96-119, 2015. 
[28] J. Vaish and S. K. Pal, "Geological mapping of Jharia coalfield, India using GRACE EGM2008 gravity data: a vertical derivative approach," Geocarto International, vol. 30, no. 4, pp. 388-401, 2015.

[29] C. Amante and B. W. Eakins, "ETOPO1 1 arc minute global relief model: procedures, data sources and analysis," NOAA Technical Memorandum NESDIS NGDC-24, 2009.

[30] H. Moritz, Advanced physical geodesy, Karlsruhe: Wichmann, Tunbridge, England, 1980.

[31] R. Forsberg and C. C. Tscherning, An Overview Manual for the GRAVSOFT Geodetic Gravity Field Modelling Programs. $D R A F T$, Contract report for JUPEM, Copenhagen, 1st edition, 2008.

[32] A. Zaki, A. H. Mansi, M. Selim, M. Rabah, and G. El-Fiky, "Comparison of satellite altimetric gravity and global geopotential models with shipborne gravity in the Red Sea," Marine Geodesy, vol. 41, no. 3, pp. 258-269, 2018.

[33] K. Dimitriadis, G. A. Tselentis, and K. Thanassoulas, "A basic program for 2-D spectral analysis of gravity data and source depth estimation," Computers \& Geosciences, vol. 13, no. 5, pp. 549-560, 1987.

[34] F. A. Kadirov, "Application of the Hartley transform for interpretation of gravity anomalies in the Shamakhy-Gobustan and Absheron oil- and gas-bearing regions, Azerbaijan," Journal of Applied Geophysics, vol. 45, no. 1, pp. 49-61, 2000.

[35] H. J. Gotze and S. Krause, "The Central Andean gravity high, a relic of an old subduction complex?," Journal of South American Earth Sciences, vol. 14, no. 8, pp. 799-811, 2002.

[36] A. B. Reid, J. M. Allsop, H. Granser, A. J. Millett, and I. W. Somerton, "Magnetic interpretation in three dimensions using Euler deconvolution," Geophysics, vol. 55, no. 1, pp. 80-191, 1990.

[37] F. J. R. Syberg, "A Fourier method for the regional-residual problem of potential fields," Geophysical Prospecting, vol. 20, no. 1, pp. 47-75, 1972.

[38] B. H. Jacobsen, "A case for upward continuation as a standard separation filter for potential-field maps," Geophysics, vol. 52, no. 8, pp. 1138-1148, 1987.

[39] L. L. Nettleton, "Regionals, residuals and structures," Geophysics, vol. 19, no. 1, pp. 1-22, 1954.

[40] V. J. S. Grauch and L. Cordell, "Limitations of determining density or magnetic boundaries from the horizontal gradient of gravity or pseudogravity data," Geophysics, vol. 52, no. 1, pp. 118-121, 1987.

[41] J. D. Philips, "Processing and interpretation of aeromagnetic data for the Santa Cruz Basin-Patahonia mountains area, South Central Arizona," U.S. Geological Survey Open File Report, Arizona, 1998.

[42] R. J. Blakely and R. W. Simpson, "Approximating edges of source bodies from magnetic or gravity anomalies," Geophysics, vol. 51, no. 7, pp. 1494-1498, 1986.

[43] S. B. Lyngsie, H. Thybo, and T. M. Rasmussen, "Regional geological and tectonic structures of the North Sea area from potential field modelling," Tectonophysics, vol. 413, no. 3-4, pp. 147-170, 2006.

[44] D. T. Thompson, "EULDPH: a new technique for making computer-assisted depth estimates from magnetic data," Geophysics, vol. 47, no. 1, pp. 31-37, 1982.

[45] J. Vicat, G. Moloto-A-Kenguemba, and A. Pouclet, "Granitoids of the Proterozoic cover of the Congo craton northern edge (South- East of Cameroon and South-West of the Central
African Republic), witnesses of a post-Kibarian to pre-PanAfrican magmatic activity," Comptes Rendus de l'Académie des Sciences - Series IIA - Earth and Planetary Science, vol. 332, no. 4, pp. 235-242, 2001.

[46] K. P. R. Malquaire, O. A. M. Louise, N. Nfor, and M. D. Eliezer, "3D modelling from new and existing gravity data of an intrusive body in the northern part of Kribi-Campo sub-basin in Cameroon," International Journal of Geosciences, vol. 8, no. 8, pp. 984-1003, 2017.

[47] F. Koumetio, D. Njomo, C. N. Tatchum, K. A. P. Tokam, C. T. Tabod, and E. Manguelle-Dicoum, "Interpretation of gravity anomalies by multi-scale evaluation of maxima of gradients and 3D modelling in Bipindi region (Southwest Cameroon)," International Journal of Geosciences, vol. 5, no. 12, pp. 14151425, 2014.

[48] J. M. Nnange, V. Ngako, J. D. Fairhead, and C. J. Ebinger, "Depths to density discontinuities beneath the Adamawa Plateau region, Central Africa, from spectral analyses of new and existing gravity data," Journal of African Earth Sciences, vol. 30, no. 4, pp. 887-901, 2000.

[49] Y. N. Shandini, J. M. Tadjou, C. T. Tabod, and J. D. Fairhead, "Gravity data interpretation in the northern edge of the Congo Craton, South-Cameroon," Anuário do Instituto de Geociências, vol. 33, pp. 73-82, 2010.

[50] C. A. Basseka, Y. Shandini, and J. M. Tadjou, "Subsurface structural mapping using gravity data of the northern edge of the Congo Craton, South Cameroon," Geofizika, vol. 28, pp. 229-245, 2011. 